\title{
Characterization of Feijoa sellowiana leaves based on volatile and phenolic compound compositions and antimicrobial properties
}

\author{
Nur CEBI ${ }^{1 *} \mathbb{D}$, Osman SAGDIC ${ }^{1}$
}

\begin{abstract}
In the present research study, response surface methodology (RSM) was performed on the basis of total phenolic content of aqueous feijoa leaf extracts. The total phenolic content of experimental runs changed between 941.6 and $4347.5 \mathrm{mg}$ GAE/L. HPLC-DAD analysis was performed to monitor the phenolic profile of feijoa leaf extract. Major phenolic compounds were determined as gallic acid, catechin, syringic acid, ellagic acid, chrysin, caffeic acid, $p$-coumaric acid, ferulic acid, and quercetin. Profile of volatile compounds was determined by using GC-MS technique and limonene, linalool and caryophyllene were detected as major volatile compounds. In addition, extracts from feijoa leaves showed antimicrobial activity against Gram-positive and Gram-negative bacteria and one yeast species. Taken together, all findings enhance our understanding of further use feijoa leaves as potential source for valuable bioactive compounds in various industrial products such as dietary supplements, food products (syrups, jams), and cosmetic products.
\end{abstract}

Keywords: feijoa leaves; RSM (response surface methodology); volatile profile; phenolics; antimicrobial.

Practical Application: Implementation of RSM for maximization of the extraction of total phenolics from the feijoa leaf using the factors of extraction temperature, time, concentration, and the shaking type.

\section{Introduction}

Feijoa sellowiana, which is a species of the family Myrtaceae is mainly grown in South America, Brazil, and New Zealand (Weston, 2010). The feijoa is known as guavasteen pineapple. Guava produces its fruits in early fall and late summer (Bimakr et al., 2019). Turkey is the homeland of a wide variety of fruits due to its favorable geographic and climate conditions. Feijoa is mainly cultivated in Sakarya, Aydın, and İzmir in Turkey (Beyhan et al., 2016). Feijoa fruit involves a wide range of healthy compounds such as dietary fibre, vitamins, and antioxidants. Also, byproducts of feijoa were reported to have functional ingredients such as phytochemicals and fibres. Previous investigations reported that feijoa extracts showed beneficial effects such as anti-microbial activity, anti-cancer activity, anti-inflammatory activity, immunity-stimulating activity, and anti-oxidant activity (Weston, 2010). In addition, most of the previous reports focused on the antioxidant properties of feijoa fruit (Zhen-Zhu et al., 2011; Mosbah et al., 2018). Data from several studies suggest that fruits and leaves of feijoa have valuable phytochemicals such as flavonoids, tannins, saponins, and terpenes in their compositions (Bimakr et al., 2019). Additionally, feijoa leaves were reported to have bioactive compounds in their compositions. However, leaves were regarded as waste and further use wasn't defined for them. Very few studies focused on exploring feijoa leaves in terms of their bioactive, antimicrobial, and antioxidant properties. The study of Poodi et al. (2018) attempted to optimize the ultrasound-assisted extraction of bioactive compounds from feijoa leaves in Iran (Poodi et al., 2018). Beyhan et al. (2010) assessed the total phenolic compounds and antioxidant capacity of feijoa leaf, dry fruit, and fresh fruit (Beyhan et al., 2010). In another study, antioxidant characteristics of feijoa leaves extract were determined by spectrophotometric methods (Ming et al., 2012). Mosbah et al. (2018) comprehensively evaluated the antioxidant, antimicrobial and pharmacological properties of feijoa leaves from Tunisia. In the previous studies, it was shown that feijoa fruit extract showed high antimicrobial and antifungal properties (Mosbah et al., 2018). It was presented that RSM has been used effectively for optimization of extraction parameters of phenolics from a wide variety of foods and agricultural products. Şahin \& Şamli, (2013) determined extraction conditions for ultrasoundassisted extraction of phenolics from olive leaf extract using RSM (Şahin \& Şamli, 2013). Another previous study used RSM for optimization of extraction of phenolics from Inga edulis leaves (Silva et al., 2007).

As can be seen, up to now, very little research has been carried out on feijoa leave around the world. In the current research, we applied RSM (response surface methodology), for the first time, for optimization of aqueous extraction of phenolics from feijoa leaves. For this purpose, the effects of four factors solid(feijoa)/solvent(water) ratio, extraction temperature, extraction time, and shaking type were evaluated to find extraction condition which would maximize total phenolic content (TPC) of aqueous 
extracts of feijoa leaves. To the best of our knowledge, this is the first attempt for the evaluation of feijoa leaves from Turkey. In our research study, we optimized the extraction of phenolics from feijoa leaves using response surface methodology. Volatile content and phenolics profile were determined by using GC-MS and HPLC techniques, respectively. Antimicrobial activity was determined against selected pathogenic microorganisms.

\section{Materials and methods}

\subsection{Apparatus and reagents}

The feijoa leaves were dried by using an oven (Memmert IN110) at $40 \pm 3^{\circ} \mathrm{C}$ for $24 \mathrm{~h}$. Dried leaves were ground by using a grinder machine (Fakir, Germany) for 30 s to obtain a homogenous powder which can pass through a stainless steel sieve (mesh $595 \mu \mathrm{m}$ ). Aqueous extracts of feijoa leaves were obtained using vertical and horizontal shakers. Total phenolics concentrations were determined by using a UV-Vis spectrophotometer (Shimadzu UV-1800, Japan). HPLC profile was determined by using Shimadzu HPLC system (Shimadzu Corp., Kyoto, Japan) composed of pump (LC-20AD), oven (CTO-10ASVP), autosampler (SIL-20A $\mathrm{HT}$ ), and diode array detector (SPDM20A). Volatile content of feijoa extract was determined by using the GCMS-QP2010 gas chromatography-mass spectrometry system (Shimadzu, Milan, Italy). Folin Ciocalteu's phenol reagent, gallic acid standard, acetic acid, and acetonitrile were obtained from Sigma-Aldrich and Merck. Feijoa leaves were collected in November 2019 in Sakarya (Turkey).

\subsection{Extraction of phenolic compounds}

Dried feijoa leaves were ground using a grinder (Fakir Aromatic, Germany). Extractions were performed according to the Design Expert (Design-Expert Software (Stat-Ease Inc. ${ }^{*}$, Version 11. Minneapolis, USA). The design model included 40 experimental steps as it is shown in Table 1. Factors of the model were temperature $\left({ }^{\circ} \mathrm{C}\right)$, time ( $\left.\mathrm{min}\right)$, feijoa concentration $(\mathrm{g} / \mathrm{mL})$, and shaking style (horizontal or vertical). Extraction temperature $\left(25-100^{\circ} \mathrm{C}\right)$, time (5-30 $\mathrm{min}$ ) and feijoa concentration $(25-100 \mathrm{mg} / \mathrm{mL})$ were shown for each batch. In the extraction process, only aqueous solutions of feijoa leaves were prepared according to the experimental pattern in Table 1. Extracts were centrifuged at $5000 \mathrm{xg}$ for $15 \mathrm{~min}$ and samples were filtered through an ordinary filter paper (Whatman, thickness: $1 \mathrm{~mm}$ ). The filtrate was collected in a glass tube and stored at $4{ }^{\circ} \mathrm{C}$ in a refrigerator until further use.

\subsection{Determination of Total Phenolic Content (TPC)}

Total phenolics content of the feijoa extracts, which were extracted according to the experimental run (Table 1), were determined using Folin-Ciocalteu (FC) method following the previous studies (Cebi et al., 2019). $2.5 \mathrm{~mL}$ of FC reagent and $2 \mathrm{~mL}$ of sodium carbonate solution (7.5\%) were added to $0.5 \mathrm{~mL}$ of diluted feijoa extract. Samples were incubated in the dark at room temperature for $30 \mathrm{~min}$. Afterwards, absorbance was measured at $760 \mathrm{~nm}$ using a UV-Visible spectrophotometer. Obtained results were presented as mg gallic acid equivalents per liter (mg GAE/L) of feijoa extract.

\subsection{HPLC analysis of feijoa extract}

HPLC analysis of feijoa extract was attained with some modifications in the previous studies (Kim et al., 2008). A HPLC coupled diode array detector (HPLC-DAD) system was used in experiments. HPLC system (Shimadzu) included pump, detector, autosampler, oven, degasser, and communications bus module (Shimadzu Corp., Kyoto, Japan). Standard calibration curves were prepared by using the analytical grade standards of gallic acid, protocatechuic acid, $p$-hydroxybenzoic acid, caffeic acid, chlorogenic acid, syringic acid, $o$-coumaric acid, $m$-coumaric acid, $p$-coumaric acid, rutin, ferulic acid, myricetin, quercetin, kaempferol, and chrysin (Sigma-Aldrich). Quite linear $\mathrm{R}^{2}$ values of 0.999 were obtained for all included standards between the concentration range of 1.95 and $156.25 \mathrm{ppm}(\mathrm{mg} / \mathrm{L})$. A C-18 reversed-phase column (GL Sciences, Intersil ${ }^{\circ}$ ODS, $250 \mathrm{~mm} \times 4.6 \mathrm{~mm} \times 5 \mu \mathrm{m}$ ) was used for separation phenolic compounds at $40{ }^{\circ} \mathrm{C}$ oven temperature. The selected wavelengths were 280, 290, 320, and $360 \mathrm{~nm}$ for UV detection. Mobile phase A (distilled water with $0.1 \%$ acetic acid) and mobile phase B (acetonitrile with $0.1 \%$ acetic acid) were used for separation at $1 \mathrm{~mL} / \mathrm{min}$ flow rate. The injection volume was $20 \mu \mathrm{L}$. The gradient was $10 \% \mathrm{~B}(0-2 \mathrm{~min}), 10-30 \% \mathrm{~B}(2-27 \mathrm{~min})$, $30-90 \%$ B (27-50 min), and 90-100\% B (51-60 min). HPLC-DAD results are presented as $\mathrm{mg} / \mathrm{g}$ feijoa leaf.

\subsection{Static HS-GC/MS analysis of feijoa leaves}

Feijoa leaves were ground by a spice grinder machine (Fakir Aromatic, Germany). $4 \mathrm{~g}$ of ground feijoa leaves were placed in $20 \mathrm{~mL}$ headspace vials. Samples were heated and agitated at $70^{\circ} \mathrm{C}$ for $15 \mathrm{~min}$ by the autosampler system. $500 \mathrm{rpm}$ agitation speed was implemented with $500 \mu \mathrm{l}$ injection volume.

Head space/gas chromatography-mass spectrometry analysis of feijoa leaves was performed with slight modifications in the previously described methodology of Cebi et al. (2019). GCMS-QP2010 (Shimadzu, Milan, Italy) combined with a CTC-Combi-PAL-autosampler was used in the head space/gas chromatography-mass spectrometry analysis. Separation of volatile compounds were obtained by using Rtx-5MS fused silica capillary column ( $30 \mathrm{~m}$ x $0.25 \mathrm{~mm}$ x $0.25 \mu \mathrm{m}$ ) with the carrier gas Helium. The oven temperature was set as the following procedure: $40{ }^{\circ} \mathrm{C}(3 \mathrm{~min}) ; 40-176^{\circ} \mathrm{C}\left(8^{\circ} \mathrm{C} / \mathrm{min}\right)$; and $176^{\circ} \mathrm{C}(20 \mathrm{~min})$. The injector temperature, pressure value, and the linear velocity were $150^{\circ} \mathrm{C}, 95.8 \mathrm{kPa}$ and $47.1 \mathrm{~cm} / \mathrm{s}$, respectively.

Interface temperature and ion source temperature were programmed as $280^{\circ} \mathrm{C}$ and $230^{\circ} \mathrm{C}$, respectively. A mass range of $35-550 \mathrm{~m} / \mathrm{z}$ and a detector voltage of $70 \mathrm{eV}$ were employed for the mass spectroscopy analysis of samples. Spectral identification of volatile compounds was performed by using the libraries of the GC-MS instrument. The volatile composition of the leaf was determined by computer matching of scanned mass spectra of feijoa samples with commercial mass spectra libraries (NIST27 and WILEY7). The quantitative amount of each volatile compound was determined on the basis of the calculation of relative peak area to the total peak area.

\subsection{Antimicrobial activity analysis of feijoa leaves}

Antimicrobial activity of feijoa leaves was determined using the agar diffusion method as described previously (Sagdic et al., 
Table 1. Experimental design, factors, actual and predicted total phenolics of response surface model (RSM).

\begin{tabular}{|c|c|c|c|c|c|c|}
\hline Experiment (Run) & $\begin{array}{c}\text { Factor 1: } \\
\text { Temperature }\left({ }^{\circ} \mathrm{C}\right)\end{array}$ & $\begin{array}{l}\text { Factor 2: Time } \\
\qquad(\min )\end{array}$ & $\begin{array}{c}\text { Factor } 3: \\
\text { Concentration } \\
\text { solid (feijoa) / } \\
\text { solvent }(\text { water }) \\
\text { ratio }(\mathrm{mg} / \mathrm{mL})\end{array}$ & $\begin{array}{c}\text { Factor 4: Shaking } \\
\text { Type (vertical, } \\
\text { horizontal) }\end{array}$ & $\begin{array}{l}\text { Actual Total } \\
\text { Phenolics } \\
\text { (mgGAE/L) }\end{array}$ & $\begin{array}{c}\text { Predicted Total } \\
\text { Phenolics by RSM } \\
\text { model (mgGAE/L) }\end{array}$ \\
\hline 1 & 62.5 & 5 & 62.5 & vertical & 2480.49 & 2291.06 \\
\hline 2 & 25 & 30 & 100 & horizontal & 3151.22 & 3064.23 \\
\hline 3 & 62.5 & 17.5 & 62.5 & horizontal & 2274.80 & 2432.47 \\
\hline 4 & 100 & 30 & 100 & vertical & 4026.02 & 3955.93 \\
\hline 5 & 62.5 & 17.5 & 62.5 & vertical & 2169.51 & 2236.57 \\
\hline 6 & 62.5 & 17.5 & 62.5 & vertical & 2193.09 & 2236.57 \\
\hline 7 & 25 & 5 & 100 & vertical & 3057.32 & 3073.28 \\
\hline 8 & 100 & 5 & 100 & vertical & 4347.56 & 4455.44 \\
\hline 9 & 62.5 & 17.5 & 62.5 & vertical & 2229.27 & 2236.57 \\
\hline 10 & 62.5 & 17.5 & 62.5 & vertical & 2220.82 & 2236.57 \\
\hline 11 & 25 & 30 & 25 & vertical & 1023.17 & 950.23 \\
\hline 12 & 100 & 5 & 25 & horizontal & 1492.68 & 1615.63 \\
\hline 13 & 100 & 5 & 25 & vertical & 1640.24 & 1600.80 \\
\hline 14 & 62.5 & 17.5 & 62.5 & horizontal & 2272.36 & 2432.47 \\
\hline 15 & 25 & 5 & 25 & horizontal & 970.73 & 988.84 \\
\hline 16 & 100 & 30 & 100 & horizontal & 3388.21 & 3406.06 \\
\hline 17 & 62.5 & 17.5 & 25 & horizontal & 1704.07 & 1507.82 \\
\hline 18 & 25 & 30 & 100 & vertical & 2403.66 & 2478.04 \\
\hline 19 & 62.5 & 17.5 & 62.5 & vertical & 2249.59 & 2236.57 \\
\hline 20 & 25 & 5 & 25 & vertical & 1056.10 & 1161.13 \\
\hline 21 & 25 & 17.5 & 62.5 & vertical & 2372.76 & 2250.32 \\
\hline 22 & 62.5 & 17.5 & 62.5 & vertical & 2077.64 & 2236.57 \\
\hline 23 & 62.5 & 17.5 & 100 & vertical & 3248.78 & 3120.65 \\
\hline 24 & 62.5 & 5 & 62.5 & horizontal & 2260.98 & 2103.21 \\
\hline 25 & 62.5 & 30 & 62.5 & horizontal & 2044.31 & 2058.25 \\
\hline 26 & 100 & 17.5 & 62.5 & vertical & 3226.42 & 3209.10 \\
\hline 27 & 100 & 30 & 25 & horizontal & 1296.75 & 1274.12 \\
\hline 28 & 25 & 5 & 100 & horizontal & 2754.07 & 2812.65 \\
\hline 29 & 62.5 & 30 & 62.5 & vertical & 1886.18 & 1935.85 \\
\hline 30 & 62.5 & 17.5 & 62.5 & horizontal & 2328.00 & 2432.47 \\
\hline 31 & 62.5 & 17.5 & 62.5 & horizontal & 2406.00 & 2432.47 \\
\hline 32 & 62.5 & 17.5 & 100 & horizontal & 3433.26 & 3485.69 \\
\hline 33 & 62.5 & 17.5 & 62.5 & horizontal & 2451.00 & 2432.47 \\
\hline 34 & 62.5 & 17.5 & 62.5 & horizontal & 2575.00 & 2432.47 \\
\hline 35 & 100 & 30 & 25 & vertical & 1466.67 & 1485.64 \\
\hline 36 & 25 & 30 & 25 & horizontal & 1309.76 & 1387.58 \\
\hline 37 & 62.5 & 17.5 & 25 & vertical & 941.06 & 929.43 \\
\hline 38 & 100 & 17.5 & 62.5 & horizontal & 2911.38 & 2835.08 \\
\hline 39 & 25 & 17.5 & 62.5 & horizontal & 2418.29 & 2350.77 \\
\hline 40 & 100 & 5 & 100 & horizontal & 3936.59 & 3894.72 \\
\hline
\end{tabular}

2006). Strains were obtained from type culture collections of the Food Engineering Department, Chemical and Metallurgical Faculty at Yildiz Technical University, Turkey. Ten different pathogenic bacteria and one pathogenic yeast were chosen as test organisms were as follows; Bacillus cereus ATCC 11778, Bacillus subtilis ATCC 6633, Streptococcus mitis, Escherichia coli ATCC 25922, Salmonella typhimurium ATCC 14028, Listeria monocytogenes ATCC 13932, Klebsiella pneumoniae ATCC 43816, Pseudomonas aeruginosa ATCC 27853, Staphylococcus aureus ATCC 29213, Escherichia coli O157:H7 ATCC 43888, and Candida albicans ATCC 10251, respectively. Before the determination of antimicrobial activity, feijoa leaves were extracted using ethanolaqueous solvent $(80 \% \mathrm{v} / \mathrm{v})$. The extract was prepared with some modifications on the previous reports (Katalinic et al., 2013). The mixture of ten grams feijoa leaves and $100 \mathrm{~mL}$ of ethanolaqueous solvent $(80 \% \mathrm{v} / \mathrm{v})$ was incubated by shaking for $2 \mathrm{~h}$ at room temperature. After incubation, the extract was filtered with Whatman filter paper No. 1 and filtrate was dried under a vacuum using a rotary evaporator at $60^{\circ} \mathrm{C}$ and lyophilized to complete dryness. All pathogenic microorganisms, which were 
Table 2. RSM model statistics and ANOVA analysis.

\begin{tabular}{|c|c|c|c|c|c|}
\hline Source & $R_{\mathrm{adj},}^{\mathrm{b}}$ & $R_{\text {pre, }}^{2}$ & $p$-value & \multicolumn{2}{|c|}{$\begin{array}{c}\text { Lack of fit, }^{\mathrm{d}} \\
p \text { - value }\end{array}$} \\
\hline Reduced Cubic Model & 0.9759 & 0.9090 & $<0.0001$ & \multicolumn{2}{|c|}{0.0580} \\
\hline Linear & 0.8880 & 0.8598 & $<0.0001$ & \multicolumn{2}{|c|}{0.0001} \\
\hline 2FI & 0.9201 & 0.8711 & 0.0126 & \multicolumn{2}{|c|}{0.0005} \\
\hline Quadratic & 0.9480 & 0.8823 & 0.0026 & \multicolumn{2}{|c|}{0.0031} \\
\hline Cubic & 0.9753 & 0.7541 & 0.0079 & \multicolumn{2}{|c|}{0.0375} \\
\hline Source & Sum of Squares & $\mathrm{DF}^{\mathrm{e}}$ & Mean Square & F-value & p-value ${ }^{f}$ \\
\hline Model $^{a}$ (reduced cubic model) & 26960000 & 19 & 1419000 & 84,1 & $<0.0001$ \\
\hline$A$-extraction temperature & 2603000 & 1 & 2603000 & 154.26 & $<0.0001$ \\
\hline$B$-extraction time & 200200 & 1 & 200200 & 11.86 & 0.0026 \\
\hline$C$-feijoa concentration & 21730000 & 1 & 21730000 & 1287.52 & $<0.0001$ \\
\hline$D$-shaking type & 162400 & 1 & 162400 & 9.62 & 0.0056 \\
\hline $\mathrm{AB}$ & 103800 & 1 & 103800 & 6.15 & 0.0221 \\
\hline $\mathrm{AC}$ & 488400 & 1 & 488400 & 28.94 & $<0.0001$ \\
\hline $\mathrm{AD}$ & 281400 & 1 & 281400 & 16.68 & 0.0006 \\
\hline $\mathrm{BD}$ & 120300 & 1 & 120300 & 7.13 & 0.0147 \\
\hline $\mathrm{A}^{2}$ & 587400 & 1 & 587400 & 34.81 & $<0.0001$ \\
\hline $\mathrm{B}^{2}$ & 310000 & 1 & 310000 & 18.37 & 0.0004 \\
\hline $\mathrm{ABD}$ & 174700 & 1 & 174700 & 10.35 & 0.0043 \\
\hline $\mathrm{A}^{2} \mathrm{D}$ & 152200 & 1 & 152200 & 9.02 & 0.007 \\
\hline$C^{2} \mathrm{D}$ & 104600 & 1 & 104600 & 6.2 & 0.0217 \\
\hline Residual & 337500 & 20 & 16874.77 & & \\
\hline Lack of fit & 249400 & 10 & 24942.05 & 2.83 & 0.058 \\
\hline Pure Error & 88075.01 & 10 & 8807.5 & & \\
\hline Cor Total & 27300000 & & & & \\
\hline
\end{tabular}

${ }^{a}$ The Model $F$-value of 84.10 implies the model is significant. There is only a $0.01 \%$ chance that an $F$-value this large could occur due to noise; b,c The Predicted $R^{2}$ of 0.9090 is in reasonable agreement with the Adjusted $R^{2}$ of 0.9759 ; i.e. the difference is less than 0.2 ; ${ }^{\mathrm{d}}$ The lack of fit $\mathrm{p}$ - value of 0.058 indicate that lack of fit is not significant; ${ }^{\mathrm{e}} \mathrm{Degrees}$ of freedom; ${ }^{\mathrm{f}} \mathrm{p}$-values less than 0.05 indicate model terms are significant. In this case A. B. C. D. AB. AC. AD. BD. $\mathrm{A}^{2}$. B ${ }^{2}$. ABD. $\mathrm{A}^{2} \mathrm{D} . \mathrm{C}^{2} \mathrm{D}$ are significant model terms.

stored at $-80{ }^{\circ} \mathrm{C}$, were inoculated in $1 \%$ ratio in Tryptic Soy Broth (Merck-Darmstadt, Germany) and incubated at $37^{\circ} \mathrm{C}$ for 24 h. Tryptic Soy Agar (Merck-Darmstadt, Germany) was prepared and autoclaved at $121^{\circ} \mathrm{C}$ for $15 \mathrm{~min}$. After autoclave, agar was cooled at $40{ }^{\circ} \mathrm{C}$ and bacteria were inoculated in $1 \%$ ratio. After inoculation agar was poured into the petri dishes. Four wells were cut in the Tryptic Soy Agar with a 5-mm cooled flamed cork borer. Feijoa leaves extracts were dissolved with sterile deionized water in the ratio of $1: 20(\mathrm{~g} / \mathrm{mL})$ and $20 \mu \mathrm{L}$ of extracts were inoculated into the three wells, sterile deionized water was used as a control. Plates were incubated at $37^{\circ} \mathrm{C}$ for $24 \mathrm{~h}$ and the diameter $(\mathrm{mm})$ of inhibition zones was measured and all tests were performed in triplicate.

\subsection{Experimental design, modeling and optimization}

\section{Response surface methodology}

Response surface methodology (RSM) was employed for investigation of the effects of four factors in the total phenolics contents of aqueous feijoa extracts. In this study, RSM was used for the evaluation of four factors on one response. DesignExpert Software (Stat-Ease Inc. ${ }^{\circ}$, Version 11. Minneapolis) was used for RSM. In this study, the factors (independent variables) were solid(feijoa)/solvent(water) ratio $\left(\mathrm{mg} / \mathrm{mL}, X_{3}\right)$, extraction temperature $\left({ }^{\circ} \mathrm{C}, X_{1}\right)$, extraction time ( $\left.\mathrm{min}, X_{2}\right)$, and shaking type (vertical or horizontal, $X_{4}$ ) and the response (dependent variable) was the total phenolic content (TPC, $\mathrm{mg} / \mathrm{L}, \mathrm{Y}$ ). The Central Composite Design (CCD) indicating extraction conditions and the responses of TPC are presented in Table 1. The design type and the design model were central composite and reduced cubic, respectively. The data collected were fitted by multiple regressions to obtain a quadratic reduced cubic model and regression coefficients were obtained.

\section{Results and discussion}

\subsection{Response Surface Methodology (RSM)}

Experimental design, factors, actual and predicted total phenolic contents obtained by RSM model (central composite design) are presented in Table 1. The reduced cubic model was selected because of the capability to present the best correlation between the dependent variable (total phenolic content) and independent variables (extraction temperature-A, extraction time- $B$, feijoa leaf concentration-C and shaking type-D) when compared to linear, interactive and quadratic models). Forty experimental runs were performed and details are presented in Table 1. In addition, measured (actual) and predicted TPC are presented in Table 1. The yield of the TPC ranged from 941.06 to $4347.56 \mathrm{mg} \mathrm{GAE} / \mathrm{L}$ and maximum TPC was observed for the $8^{\text {th }}$ run under the experimental conditions of $\mathrm{A}=100^{\circ} \mathrm{C}$; $\mathrm{B}=5 \mathrm{~min} ; \mathrm{C}=100 \mathrm{mg} / \mathrm{mL}$ and $\mathrm{D}=$ vertical shaking. $\mathrm{RSM}$ model statistics are presented in Table 2 . As it can be seen, reduced 
cubic model provided the most favorable statistical values for modeling of the interrelation between independent variables (factors) and dependent variable (TPC). In other words, the highest adjusted coefficient $\left(R_{\text {adj }}^{2}\right)$, predicted coefficient $\left(R^{2}{ }_{\text {pre }}\right)$, and the lowest $p$-value were obtained by reduced cubic model. ANOVA results for linear and combination relationships are presented in Table 2. $P$-values for linear and combination effects of independent factors on the response (total phenolic content) are presented in Table 2. $P$-values for extraction temperature (A), feijoa concentration (B) were determined to be lower than 0.0001 . $P$-values less than 0.05 indicate these terms are significant. In this model, the linear effects of A (extraction temperature), B (extraction time), $\mathrm{C}$ (feijoa concentration), and D (shaking type) are significant. In addition, the combination effects of $\mathrm{AB}, \mathrm{AC}$, $\mathrm{AD}, \mathrm{BD}, \mathrm{A}^{2}, \mathrm{~B}^{2}, \mathrm{ABD}, \mathrm{A}^{2} \mathrm{D}$, and $\mathrm{C}^{2} \mathrm{D}$ are significant. Adjusted and predicted $\mathrm{R}^{2}$ values of the RSM model were determined to be 0.9759 and 0.9090 , respectively. The difference between predicted and adjusted $\mathrm{R}^{2}$ values is less than 0.2 and this shows that adjusted and predicted $\mathrm{R}^{2}$ values are in good agreement. The $F$-value of the model is 84.10 and this implies the model is significant. There is only a $0.01 \%$ chance that an $F$-value this large could occur due to noise. The lack of fit value of the model was found to be 0.0580 and indicating that lack of fit is not significant. This means that the model is extremely accurate without any noise.

The response surface model equation which relate the influence of variables to the total phenolic content is presented by the following equation $(R=$ total phenolic content, $A=$ extraction temperature, $B=$ extraction time, $C=$ feijoa concentration, $D=$ shaking type):

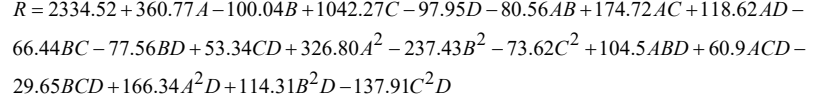

RSM model was developed through 40 runs and residual analysis was performed for evaluation of the response surface model of total phenolic content. The normal plot of residuals, predicted versus actual, residuals versus run, and residual versus predicted are presented in Figure 1A, 1B, 1C, and 1D, respectively. As it can be seen in Figure 1A, favorable correlation was observed between experimental and predicted values since all data dispersed on a straight line. Similarly, the graph of predicted versus actual values are presented in Figure 1B. The actual values are quite close to the predicted ones as perfectly linear correlation were observed between them. The data points are splitted evenly by the 45 -degree line, which describes the perfect fit between predicted and actual values.

Figure 1C shows the residuals calculated versus the experimental runs, indicating that there were positive and negative runs. The existence of tendency to have runs of positive and negative residuals is explained by the presence of a certain correlation. This is a plot of the residuals versus the experimental run order. It provides a check for lurking variables that may have influenced
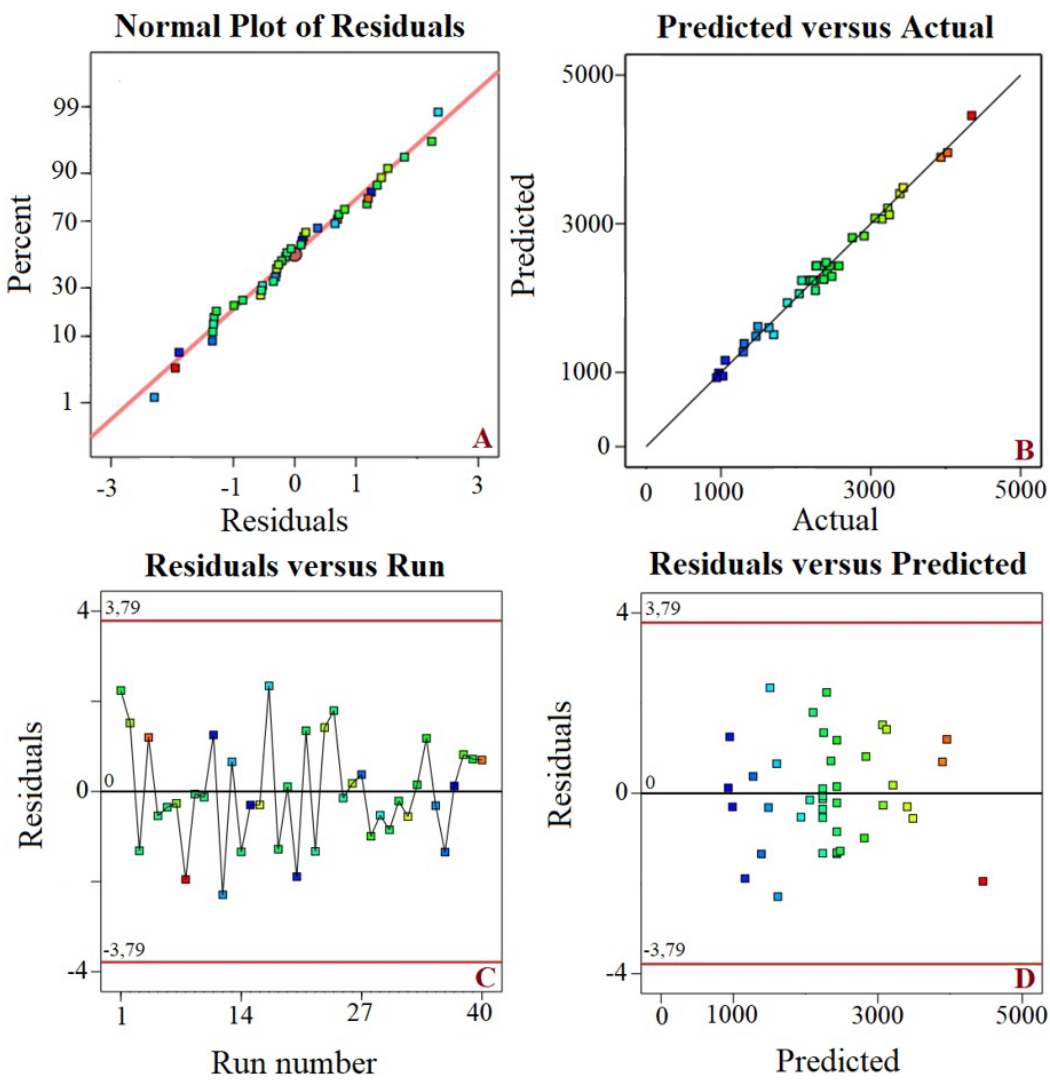

Figure 1. Normal plot of residuals for total phenolic content, TPC. (A) predicted versus actual values, (B) residuals versus experimental run number (C), residuals versus predicted values (D). 

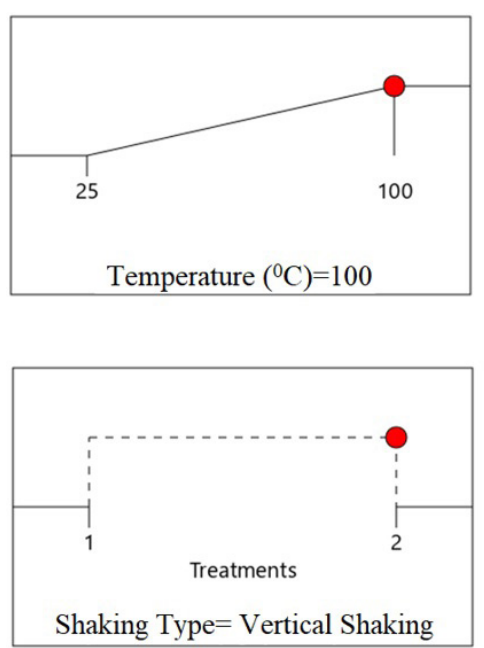
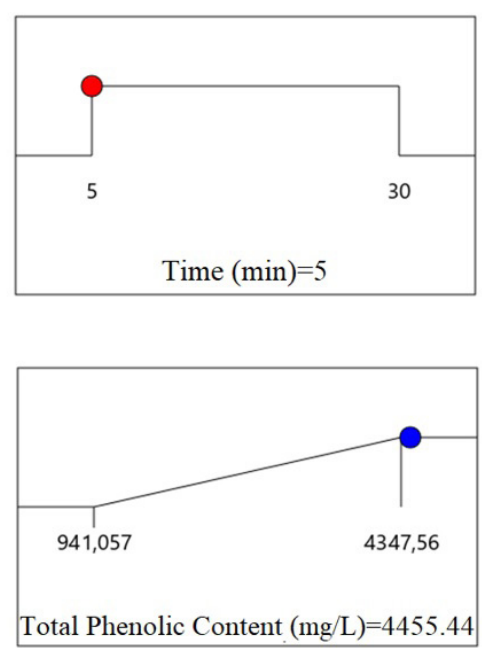

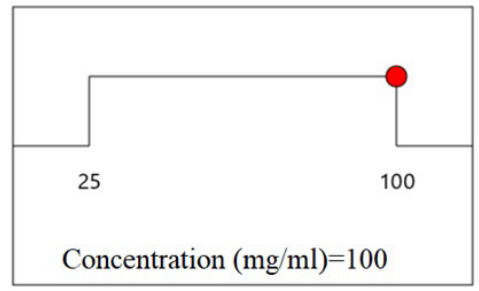

Desirability=1

Figure 2. Output factor values for maximization of the total phenolic content by response surface methodology design (Desirability=1).

the response during the experiment. The plot should show a random scatter. Trends indicate a time-related variable lurking in the background. Residuals versus predicted plot is presented in Figure 1D; it is used for visual check for the assumption of constant variance. A random scatter with a consistent top to the bottom range of residuals across the predictions was observed on the X1 axis. No residuals were observed outside the red lines of the plot. In other words, no observation was noted that does not fit the RSM model. These results demonstrate the accuracy and precision of the developed RSM model. In addition, output factor values for the maximization of the total phenolic content by the RSM (desirability $=1$ ) are presented in Figure 2. According to the RSM model, extraction temperature, time, concentration, and the shaking type were determined as $100{ }^{\circ} \mathrm{C}, 5 \mathrm{~min}, 100(\mathrm{mg} / \mathrm{mL})$, and vertical shaking, respectively. Most significant $(p<0.0001)$ linear factors were extraction temperature and solid/solvent ratio $(\mathrm{mg} / \mathrm{mL})$ of feijoa leaf. As it can be seen, maximum phenolic extraction was obtained at maximum extraction temperature $\left(100{ }^{\circ} \mathrm{C}\right)$. The temperature was reported as a significant factor in terms of extraction of total phenolic content from leaves, an increase in the extraction temperature resulted in a rise in extracted phenolic content (Li et al., 2016). Previous studies reported that extraction temperature was the most important independent variable for the extraction of bioactive compounds from feijoa leaves and increase in the extraction temperature caused positive effect on extraction of bioactive compounds (Poodi et al., 2018). In another study, it was reported that the total phenolic content of extracts increased with increasing temperature (Ballard et al., 2009). Li et al. (2016) showed that temperature was a significant factor for the extraction of phenolics from perilla leaves and rise was observed in the total phenolic content with rising temperature (Li et al., 2016). Solid/solvent ratio $(\mathrm{mg} / \mathrm{mL})$ of feijoa leaf significantly affected the total phenolic extraction $(\mathrm{p}<0.0001)$. The maximum phenolic yield was obtained at maximum solid/solvent ratio $(100 \mathrm{mg} / \mathrm{mL})$. Previous studies reported that an increase in the solvent concentration might result in higher phenolic yield in the ethanolic or methanolic extracts of some leaves (Silva et al., 2007). However, in our study, aqueous extraction was performed from feijoa leaves and total phenolic yield increased with rising solid/solvent ratio. In a previous research study, bioactive properties of aqueous Stevia leaf extracts increased in a dose-dependent manner. In other words, radical scavenging activity raised with increasing Stevia leaf concentration in the range of $20-200 \mu \mathrm{g} / \mathrm{mL}$ (Shukla et al., 2012). In our study, $p$ value was found to be lower than 0.005 for the extraction time. Extraction time was selected between 5 and $30 \mathrm{~min}$ in the RSM model. However, the maximum phenolic yield was obtained in $5 \mathrm{~min}$ (desirability=1). Favorably, shorter extraction times may protect valuable bioactive compounds from deterioration. This result is in agreement with the reported by Poodi et al. (2018) for the extraction of bioactive compounds from feijoa leaves (Poodi et al., 2018). In addition to these results, vertical shaking was determined by RSM for maximum phenolic yield from feijoa leaves. This result may be explained with better penetration of solvent into the feijoa leaves through improved vertical shaking type with upside and downside shaking. Central Composite Design (CCD) of response surface methodology was successfully applied for the optimization of independent variables 
to maximize TPC values. Figure 2 presents the desirability value and defined factor values for the most desirable $(D=1.000)$ solution for the maximization of total phenolic content. In this study, the most desirable $(\mathrm{D}=1.000)$ solution for maximization of TPC corresponds to vertical shaking, extraction time of $5 \mathrm{~min}$, and extraction temperature of $100^{\circ} \mathrm{C}$ to obtain maximum TPC value, $4455.44 \mathrm{mg} \mathrm{GAE} / \mathrm{L}$.

\subsection{Volatile composition of feijoa leaves}

Head space/gas chromatography-mass spectrometry analysis was performed for the determination of the volatile composition of dried feijoa leaves. Retention indices and relative abundance percentages of related compounds are presented in Table 3. According to the GC-MS identification results, 20 compounds were detected in feijoa leaf. These compounds were determined by comparing the mass spectra of feijoa leaf to the library of GCMS. The most abundant volatile components were limonene, linalool, and caryophyllene at the percentages of $33.46 \%, 18.95 \%$ and $22.18 \%$, respectively. Other volatile compounds are $\alpha$-pinene, $\beta$-pinene, myrcene, $\alpha$-terpinene, $(Z)$ - $\beta$-ocimene, (E)- $\beta$-ocimene, $\gamma$-terpinene, terpineol, $\alpha$-cubebene, $\alpha$-copaene, $\beta$-bourbonene, $\alpha$-gurjunene, $\beta$-gurjunene, $\alpha$-humulene, alloaromadendrene, germacrene, and spathulenol. To the best of our knowledge, this is the first attempt for the determination of the volatile composition of feijoa leaves from Turkey. This result is in partially agreement with those reported by Mosbah et al. (2018) about the characterization of feijoa leaves growing in Tunisia. Mosbah et al. (2018) reported that major volatile components were limonene, $\beta$-caryophyllene, and aroma dendrene in the feijoa leaves from Tunisia (Mosbah et al., 2018). So far, very little research has been carried out on the subject of the volatile composition of feijoa leaves. In another study, Saj et al. (2008) reported that major volatile compounds were limonene, $\beta$-caryophyllene and $\alpha$-pinene, $\beta$-pinene and estragole in the feijoa leaves (Saj et al., 2008). Our results are quite coherent with previous studies and mostly limonene, linalool, and caryophyllene were determined as volatile compounds in the feijoa leaves cultivated in Turkey. According to our results, the most abundant volatile compound was limonene with $33.46 \%$ relative abundance ratio. Previous contributions reported that D-limonene showed antioxidant, anticancerogenic, and anti-inflammatory properties with desirable flavor and sensory properties (Sun, 2007). Functional and favorable properties of limonene may contribute to further utilization of feijoa in functional food products in the food sector.

\subsection{Phenolic composition of feijoa leaves}

Quantitative analyses were performed for the important phenolic standards, which are presented in Table 4. Phenolic composition of the aqueous feijoa leaf extract is presented in Table 4 and Figure 3. The extract of run eight is used for the HPLC analysis. Gallic acid, catechin, syringic acid, ellagic acid, chrysin, caffeic acid, $p$-coumaric acid, ferulic acid, and quercetin were detected as phenolic compounds. Major compounds were catechin, quercetin, and ellagic acid. Our results were quite compatible with previous ones. Up to now, very limited studies were performed for the evaluation of the phenolic content of feijoa. Poodi et al. (2018) reported that major phenolic compounds were
Table 3. Volatile composition of the feijoa leaf from Turkey.

\begin{tabular}{cccr}
\hline Number & Compound & $\mathrm{RI}^{\mathrm{a}}$ & $\%$ content $^{\mathrm{b}}$ \\
\hline 1 & $\alpha$-pinene & 939 & $0.6 \pm 0.32$ \\
2 & $\beta$-pinene & 980 & $0.5 \pm 0.21$ \\
3 & myrcene & 991 & $0.9 \pm 0.12$ \\
4 & $\alpha$-terpinene & 1018 & $0.3 \pm 0.15$ \\
5 & limonene ${ }^{\mathrm{c}}$ & 1031 & $\mathbf{3 3 . 4 6} \pm 1.21$ \\
6 & $(Z)$ - $\beta$-ocymene & 1040 & $1.5 \pm 0.84$ \\
7 & $(E)-\beta$-ocymene & 1050 & $0.8 \pm 0.11$ \\
8 & $\gamma$-terpinene & 1062 & $0.7 \pm 0.55$ \\
9 & linalool & 1098 & $\mathbf{1 8 . 9 5} \pm 1.34$ \\
10 & terpineol & 1189 & $6.76 \pm 0.82$ \\
11 & $\alpha$-cubebene & 1347 & $0.9 \pm 0.14$ \\
12 & $\alpha$-copaene & 1372 & $1.02 \pm 0.25$ \\
13 & $\beta$-bourbonene & 1384 & $2.55 \pm 0.63$ \\
14 & $\alpha$-gurjunene & 1412 & $1.35 \pm 0.72$ \\
15 & caryophyllene & 1418 & $\mathbf{2 2 . 1 8} \pm 1.21$ \\
16 & $\beta$-gurjunene & 1432 & $1.5 \pm 0.58$ \\
17 & $\alpha$-humulene & 1455 & $1.08 \pm 0.45$ \\
18 & alloaromadendrene & 1463 & $0.25 \pm 0.13$ \\
19 & germacrene-d & 1576 & $1.09 \pm 0.44$ \\
20 & spathulenol & 1580 & $3.6 \pm 0.71$ \\
& & Total Identified & $\mathbf{9 9 . 9}$ \\
\hline
\end{tabular}

${ }^{\text {a}} \mathrm{RI}$ : Retention index relative to n-alkanes (C8-C40) on Rtx-5MS fused silica capillary column $(30 \mathrm{~m} \times 0.25 \mathrm{~mm}$ (internal diameter) $0.25 \mu \mathrm{m})$; ${ }^{\text {b }} \%$ Content: The relative compositions of the constituents obtained by GC-MS peak analysis; ${ }^{\mathrm{C}}$ Most abundant compounds are presented bold.

Table 4. Phenolic composition of the feijoa leaf extract sample with maximum total phenolic content.

\begin{tabular}{ccc}
\hline $\mathrm{N}^{\circ}$ & $\begin{array}{c}\text { Bioactive phenolic } \\
\text { compounds }\end{array}$ & $\begin{array}{c}\text { Major phenolic } \\
\text { content }(\mathrm{mg} / \mathrm{g})\end{array}$ \\
\hline 1 & gallic acid & 32.25 \\
2 & catechin & 46.45 \\
3 & syringic acid & 0.51 \\
4 & elagic acid & 41.69 \\
5 & chrysin & 20.74 \\
6 & caffeic acid & 12.00 \\
7 & p-coumaric acid & 2.61 \\
8 & ferulic acid & 5.40 \\
9 & quercetin & 42.03 \\
\hline
\end{tabular}

determined as gallic acid, catechin, rutin, ferulic acid, quercetin apigenin, and gallic acid was obtained at the highest concentration by the ultrasound-assisted extraction of feijoa leaf (Tehran, Iran). Common phenolic compounds were gallic acid, catechin, ferulic acid, and quercetin with the current research study. Bimakr et al. (2019) determined the phenolic composition of feijoa leaf extract, which was obtained by modified supercritical carbon dioxide extraction. They reported that the main phenolic compounds were gallic acid, catechin, rutin, ferulic acid, quercetin, and apigenin. Mousavi et al. (2018) reported that feijoa leaves from Iran, included gallic acid, catechin, rutin, ferulic acid, apigenin, and quercetin in their compositions. While the most abundant phenolic compound was gallic acid $(98.18 \mathrm{mg} / \mathrm{g})$, least abundant one was apigenin $(19.67 \mathrm{mg} / \mathrm{g})$ obtained by supercritical carbon 


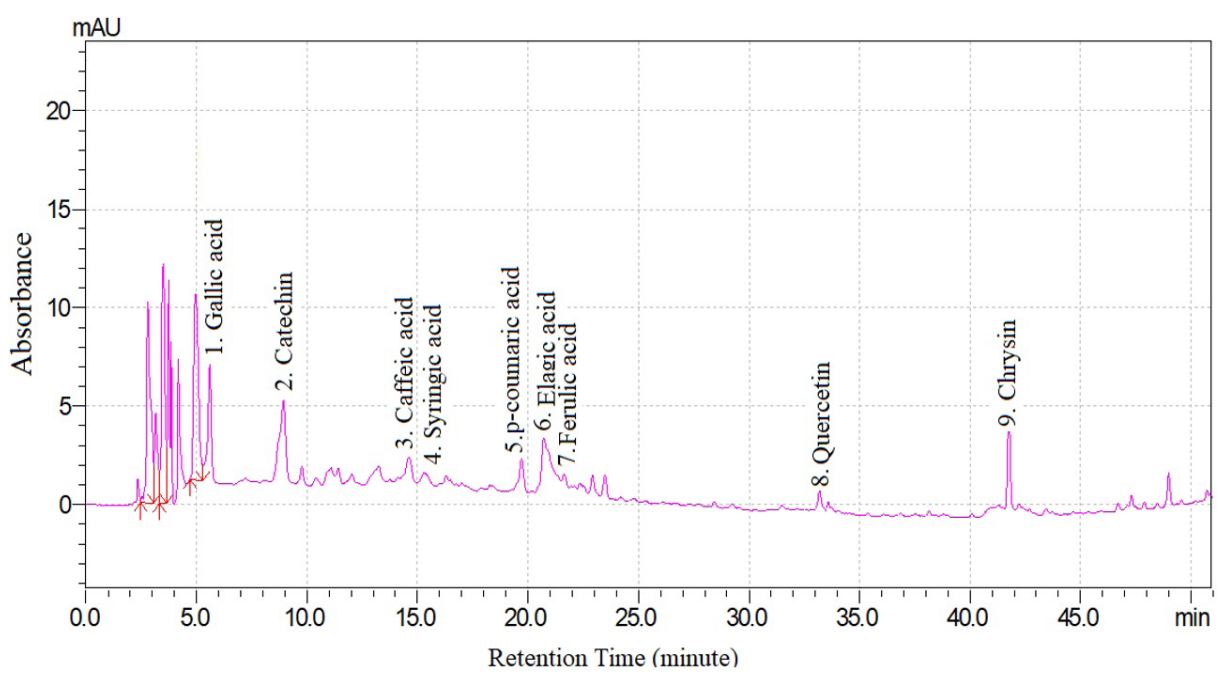

Figure 3. HPLC chromatogram of the feijoa leaf extract with maximum total phenolic content.

Table 5. Antibacterial activities of Feijoa sellowiana leaves extract.

\begin{tabular}{cc}
\hline Test microorganisms & Inhibition zone $(\mathrm{mm})$ \\
\hline Gram positive bacteria & \\
Bacillus cereus ATCC 11778 & $17.50 \pm 0.09$ \\
Bacillus subtilis ATCC 6633 & $8.33 \pm 0.12$ \\
Streptococcus mitis & $13.83 \pm 0.03$ \\
Listeria monocytogenes ATCC 13932 & $15.67 \pm 0.06$ \\
Staphylococcus aureus ATCC 29213 & $13.33 \pm 0.03$ \\
Gram negative bacteria & \\
Escherichia coli ATCC 25922 & $14.00 \pm 0.10$ \\
Salmonella Typhimurium ATCC 14028 & $13.83 \pm 0.08$ \\
Klebsiella pneumoniae ATCC 43816 & $15.00 \pm 0.05$ \\
Pseudomonas aeruginosa ATCC 27853 & $13.33 \pm 0.03$ \\
Escherichia coli O157:H7 ATCC 43888 & $12.67 \pm 0.03$ \\
Yeast & \\
Candida albicans ATCC 10251 & $12.50 \pm 0.05$ \\
\hline
\end{tabular}

dioxide extraction $\left(40^{\circ} \mathrm{C}, 150\right.$ bar and $\left.60 \mathrm{~min}\right)$ (Mousavi et al., 2018). In another study, Aniq et al. (2019) reported that phenolic composition of the leaves of feijoa mostly included gallic acid, catechin, epicatechin, cafeic acid, and ellagic acid. The most abundant phenolic compound was ellagic acid, according to their UFLC-MS/MS analysis results (Aniq et al., 2019). Our results showed that major phenolic compounds detected in feijoa leaves from Turkey were catechin, quercetin, ellagic acid, and gallic acid with the concentration of $46.45 \mathrm{mg} / \mathrm{g}, 42.03 \mathrm{mg} / \mathrm{g}$, $41.69 \mathrm{mg} / \mathrm{g}$, and $32.25 \mathrm{mg} / \mathrm{g}$, respectively. In general, similar phenolic compounds were observed in the feijoa leaves of different countries. However, disparities were observed in the quantities of phenolic compounds of different countries. In accordance with the present results, previous studies have demonstrated that phenolic composition of same species may vary related to the regional differences (Ouerghemmi et al., 2016). For example, Ouerghemmi et al. (2016) reported that phenolic composition of Rosa moschata showed differences between the Tunisian regions of Nabeul, Bizerte, and Zaghouan. Our findings show that feijoa leaves from Turkey could be used as a potential source for valuable phenolic compounds such as gallic acid, catechin, quercetin, and ellagic acid.

\subsection{Antimicrobial activity of feijoa leaves}

Previous reports mostly evaluated the antimicrobial activity of feijoa fruit and feijoa fruit showed antimicrobial activity against Gram-positive and Gram-negative bacteria, as well as fungi (Beyhan et al., 2010; Vuotto et al., 2000). Aqueous feijoa fruit extract showed more antimicrobial activity on Gram-negative bacteria (Enterobacter aerogenes, Enterobacter cloacae and Pseudomonas aeruginosa) when compared to Gram-positive bacteria (Vuotto et al., 2000). To the best of our knowledge, this study is the first effort for the determination of antimicrobial properties of feijoa leaves extract from Turkey. Test microorganisms and inhibition zones are presented in Table 5. Deionized water (control) had no inhibitory effects on the evaluated microorganisms. Antimicrobial activity of feijoa leaf was determined by using agar diffusion method against ten bacteria (5 Gram-positive and 5 Gram-negative) and 1 yeast. Inhibition zones (IZ) varied between $8.33 \pm 0.12 \mathrm{~mm}$ and $17.50 \pm 0.09 \mathrm{~mm}$. As it can be seen from Table 5, Bacillus cereus was the most sensitive bacteria with IZ value of $17.50 \pm 0.09 \mathrm{~mm}$. Mosbah et al. (2018) evaluated the antimicrobial properties of feijoa leaves extract from Tunisia and they observed lower IZ value for Bacillus cereus ATCC 11778. In general our IZ values were higher than the ones determined by Mosbah et al. (2018). However quite similar IZ value was obtained for Escherichia coli O157:H7 ATCC 43888 and Escherichia coli ATCC35218 as approximately $12.6 \mathrm{~mm}$. In our study, the most resistant bacteria was determined as Bacillus subtilis ATCC 6633 with IZ value of $8.33 \pm 0.12 \mathrm{~mm}$. In addition, IZ value for Candida albicans ATCC 10251 was determined as $12.50 \pm 0.05 \mathrm{~mm}$. Mosbah et al. (2018) determined the IZ value as $6.66 \pm 0.33 \mathrm{~mm}$ for Candida albicans ATCC 2019. As it can been seen, IZ variations were observed between results from the feijoa leaves of different countries. This situation may be related to the geographic conditions, which may affect the chemical composition of the feijoa leaves. It was reported that bioactive compounds such as 
phenolics and volatile ingredients in the herbs determines the antimicrobial, antioxidant and antifungal properties of related herbs (Tulukcu et al., 2019).

\section{Conclusions}

In summary, the present study will serve a base for future studies about the evaluation of the phenolic composition, volatile composition, and antimicrobial activity of feijoa leaves from Turkey. In summary, our research developed a RSM model for the extraction of total phenolic compounds from feijoa leaves. Extraction temperature, time, concentration, and the shaking type were determined by the RSM model as $100^{\circ} \mathrm{C}$, $5 \mathrm{~min}, 100(\mathrm{mg} / \mathrm{mL})$, and vertical shaking, respectively, for maximization of phenolic compounds. Significant factors were extraction temperature, extraction time, solid/solvent ratio $(\mathrm{mg} / \mathrm{mL})$, and shaking type. Most significant $(p<0.0001)$ linear factors were extraction temperature and solid/solvent ratio $(\mathrm{mg} / \mathrm{mL})$ of feijoa leaf. In addition, major phenolic compounds were determined as gallic acid, catechin, syringic acid, ellagic acid, chrysin, caffeic acid, $p$-coumaric acid, ferulic acid, and quercetin. In other words, the extract of leaves has high phenolic content with valuable phenolic compounds, which have bioactive properties. In addition, extracts from feijoa leaves showed antimicrobial activity against Gram-positive and Gram-negative bacteria, and one yeast species. Furthermore, volatile profile of feijoa leaf was determined by using GC-MS technique and limonene, linalool and caryophyllene were detected as major volatile compounds. These findings enhance our understanding of further use of feijoa leaves as potential source for valuable bioactive compounds in various industrial products such as dietary supplements, food products (syrups, jams), cosmetic products, etc. Further investigation including high-resolution chromatographic techniques, will provide deeper exploration to discover unknown chemical structures which may have valuable bioactive properties such as antioxidative, anti-inflammatory, antimutagenic, anticarcinogenic, antiangiogenic, antiobesity, hypocholesterolemic, antiatherosclerotic, antidiabetic, antibacterial, and antiviral, anti-aging.

\section{Conflict of interest}

The authors declare no competing financial interest.

\section{Author contributions}

N. Cebi designed the study, performed the analyses and interpreted the results. O. Sagdic designed the study and interpreted results.

\section{Acknowledgements}

Authors would like to thank to the Yildiz Technical University Food Engineering Department students Feyza Atilgan, Aslihan Ergul, Cemre Gul, and Hamza Goktas for their technical assistance.

\section{References}

Aniq, F. O., Elfarnini, M., Abdel-hamid, A. A., \& Blaghen, M. (2019). Chemical composition of isoflavones compounds and antioxidants from Feijoa sellowiana leaves. GSC Biological and Pharmaceutical Sciences, 9(1), 120-124. http://dx.doi.org/10.30574/gscbps.2019.9.1.0157.

Ballard, T. S., Mallikarjunan, P., Zhou, K., \& O’keefe, S. F. (2009). Optimizing the extraction of phenolic antioxidants from peanut skins using response surface methodology. Journal of Agricultural and Food Chemistry, 57(8), 3064-3072. http://dx.doi.org/10.1021/ jf8030925. PMid:19284759.

Beyhan, Ö., Demir, T., Eyduran, P. A., \& Akın, M. (2016). Dünyada Feijoa (Feijoa sellowiana Berg.)Yetiştiriciliği ve Ülkemiz Meyveciliği Açısından Feijoa Yetiştiriciliğinin Yeri ve Önemi. Türk Bilimsel Derlemeler Dergisi, 9(2), 16-19.

Beyhan, Ö., Elmasta, M., \& Gedikli, F. (2010). Total phenolic compounds and antioxidant capacity of leaf, dry fruit and fresh fruit of feijoa (Acca sellowiana, Myrtaceae). Journal of Medicinal Plants Research, 4(11), 1065-1072.

Bimakr, M., Ghoreishi, S. M., Ganjloo, A., \& Mousavi, M. (2019). Modified supercritical carbon dioxide extraction of biologically active compounds from Feijoa Sellowiana leaves. International Journal of Food Engineering, 20180342(7), 1-16. http://dx.doi. org/10.1515/ijfe-2018-0342.

Cebi, N., Sagdic, O., Basahel, A. M., Balubaid, M. A., Taylan, O., Yaman, M., \& Yilmaz, M. T. (2019). Modeling and optimization of ultrasound-assisted cinnamon extraction process using fuzzy and response surface models. Journal of Food Process Engineering, 42(2), 1-15. http://dx.doi.org/10.1111/jfpe.12978.

Katalinic, V., Mozina, S. S., Generalic, I., Skroza, D., Ljubenkov, I., \& Klancnik, A. (2013). Phenolic profile, antioxidant capacity, and antimicrobial activity of leaf extracts from six vitis vinifera $\mathrm{L}$. Varieties. International Journal of Food Properties, 16(1), 45-60. http://dx.doi.org/10.1080/10942912.2010.526274.

Kim, M. Y., Seguin, P., Ahn, J. K., Kim, J. J., Chun, S. C., Kim, E. H., Seo, S. H., Kang, E. Y., Kim, S. L., Park, Y. J., Ro, H. M., \& Chung, I. M. (2008). Phenolic compound concentration and antioxidant activities of edible and medicinal mushrooms from Korea. Journal of Agricultural and Food Chemistry, 56(16), 7265-7270. http://dx.doi. org/10.1021/jf8008553. PMid:18616260.

Li, H.-Z., Zhang, Z.-J., Xue, J., Cui, L.-X., Hou, T., Li, X.-J., \& Chen, T. (2016). Optimization of ultrasound-assisted extraction of phenolic compounds, antioxidants and rosmarinic acid from perilla leaves using response surface methodology. Food Science and Technology, 36(4), 686-693.

Ming, C., Liu, H. R., \& Dan, R. W. (2012). Study on the antioxidant activity of extract from Feijoa sellowiana leaves. Guoshu Xuebao, 29(4), 593-597.

Mosbah, H., Louati, H., Boujbiha, M. A., Chahdoura, H., Snoussi, M., Flamini, G., Ascrizzi, R., Bouslema, A., Achour, L., \& Selmi, B. (2018). Phytochemical characterization, antioxidant, antimicrobial and pharmacological activities of Feijoa sellowiana leaves growing in Tunisia. Industrial Crops and Products, 112, 521-531. http://dx.doi. org/10.1016/j.indcrop.2017.12.051.

Mousavi, M., Bimakr, M., Ghoreishi, S. M., \& Ganjloo, A. (2018). Supercritical Carbon Dioxide Extraction of Bioactive Compounds from Feijoa (Feijoa sellowiana) Leaves. Nutrition and Food Sciences Research, 5(3), 23-31. http://dx.doi.org/10.29252/nfsr.5.3.23.

Ouerghemmi, S., Sebei, H., Siracusa, L., Ruberto, G., Saija, A., Cimino, F., \& Cristani, M. (2016). Comparative study of phenolic composition and antioxidant activity of leaf extracts from three wild Rosa species grown in different Tunisia regions: Rosa canina L., Rosa moschata Herrm. and Rosa sempervirens L. Industrial Crops and Products, 94, 167-177. http://dx.doi.org/10.1016/j.indcrop.2016.08.019. 
Poodi, Y., Bimakr, M., Ganjloo, A., \& Zarringhalami, S. (2018). Intensification of bioactive compounds extraction from Feijoa (Feijoa sellowiana Berg.) leaves using ultrasonic waves. Food and Bioproducts Processing, 108, 37-50. http://dx.doi.org/10.1016/j.fbp.2017.12.004.

Sagdic, O., Aksoy, A., \& Ozkan, G. (2006). Evaluation of the antibacterial and antioxidant potentials of cranberry (Gilaburu, viburnum opulus L.) fruit extract. Acta Alimentaria, 35(4), 487-492. http://dx.doi. org/10.1556/AAlim.35.2006.4.12.

Şahin, S., \& Şamli, R. (2013). Optimization of olive leaf extract obtained by ultrasound-assisted extraction with response surface methodology. Ultrasonics Sonochemistry, 20(1), 595-602. http://dx.doi.org/10.1016/j. ultsonch.2012.07.029. PMid:22964032.

Saj, O., Roy, R., \& Savitha, S. (2008). Chemical composition and antimicrobial properties of essential oil of Feijoa sellowiana O. Berg. (pineapple guava). Journal of Pure \& Applied Microbiology, 2, 227-230.

Shukla, S., Mehta, A., Mehta, P., \& Bajpai, V. K. (2012). Antioxidant ability and total phenolic content of aqueous leaf extract of Stevia rebaudiana Bert. Experimental and Toxicologic Pathology, 64(7-8), 807-811.http://dx.doi.org/10.1016/j.etp.2011.02.002. PMid:21377849.
Silva, E. M., Rogez, H., \& Larondelle, Y. (2007). Optimization of extraction of phenolics from Inga edulis leaves using response surface methodology. Separation and Purification Technology, 55(3), 381-387. http://dx.doi.org/10.1016/j.seppur.2007.01.008. [h]

Sun, J. (2007). D-limonene safety and clinical applications. Alternative Medicine Review, 12(3), 259-264. PMid:18072821.

Tulukcu, E., Cebi, N., \& Sagdic, O. (2019). Chemical Fingerprinting of Seeds of Some Salvia Species in Turkey by Using GC-MS and FTIR, 8(4), 1-12.

Vuotto, M. L., Basile, A., Moscatiello, V., De Sole, P., CastaldoCobianchi, R., Laghi, E., \& Ielpo, M. T. (2000). Antimicrobial and antioxidant activities of Feijoa sellowiana fruit. International Journal of Antimicrobial Agents, 13(3), 197-201. http://dx.doi.org/10.1016/ S0924-8579(99)00122-3. PMid:10724024.

Weston, R. J. (2010). Bioactive products from fruit of the feijoa (Feijoa sellowiana, Myrtaceae): a review. Food Chemistry, 121(4), 923-926. http://dx.doi.org/10.1016/j.foodchem.2010.01.047.

Zhen-Zhu, D., Ren-Hua, H., \& Dan, W. (2011). Optimization of extraction process and antioxidant activities of the total flavonoids from Feijoa sellowiana leaves. Journal of Food Science and Biotechnology, 30, 371-375. 